\title{
Drought Analysis and Forecast Using Landsat-8 Sattelite Imagery, Standardized Precipitation Index and Time Series
}

\author{
Musa Marsel Maipauw ${ }^{*}$, Eko Sediyono, Sri Yulianto Joko $\mathbf{P}$ \\ Graduate Study in Information Systems, Faculty of Information Technology \\ Universitas Kristen Satya Wacana \\ Salatiga 50711, Jawa Tengah \\ "marselmaipauw@yahoo.com
}

\begin{abstract}
A drought is a phenomenon of shortages in water supply in an area for a long time. Drought usually occurs in areas that has little rain for a long time or in areas with low precipitation. Drought have negative impacts on many sectors such as agriculture, plantations, water resources and environment. This paper describes the results of a research that aims to analyze data to get the level of drought during four yearly periods, and predict the likelihood of drought to occur in the future. The level of drought was analyzed using the Inverse Distance Weighted (IDW) method and the Standardized Precipitation Index (SPI). Least square time series was utilized to forecast the level of drought in the near future. Data consists of drought data collected from electronic news, rainfall data from BMKG, and anual Landsat-8 satellite imagery. All data are for Western Southeast Mallucas in the range of 2015-2018. Analysis using IDW and SPI methods produce similar interpretation for year 2015, i.e. mild dryness, and fro year 2018 , i.e. no drought. However, the two methods show discrepancy in analysis of data for 2016 and 2017. The use of least square time series to forecast drought in 2019 gives SPI value of 0.03 which intepretes as normal weather (no drought) that is consistent with the result of field observation.
\end{abstract}

Keywords: Drought, inverse distance weighted, standard precipitation index, least square, time series

\section{Introduction}

A drought is a phenomenon of shortages in water supply in an area for a long time for example in the range of months or even years. Drought usually occurs in areas that has little rain for a long time or in areas with low precipitation. Drought often occurs in many part of the world, including regions in Indonesia. Indonesias geographical position between two continents and two oceans and its position on the equator are factors which contribute to dynamic weather that may cause flooding and drought. The archipelago has a tropical monsoon climate that is very sensitive to the El Nino Southern Oscillation (ENSO) anomaly [1], [2]. Nugroho (2018), Head of the BNPB Data and Public Relations Data Center, stated that an area that has once experienced a drought had a good chance to experience similar disaster in the upcoming years [3].

Drought may be considered as an imbalance between water need and water supply that the nature can be provide. Drought gives negative impact in various sectors such as agriculture, animal husbandry, plantations and forestry because the absence of water inhibits the growth of plants and slows down biological metabolism of humans and animals. A such, water availability affects economic productivity in the sectors.

Drought is a calamity to anticipate. It is very difficult, if possible, to avoid being exposed to drought and if that happens, people will suffer from many undesirable impacts. However, people can make preparations so that the effect of a drought is minimized. Such preparations will be effective if we can predict as when the disaster will take place. Efforts to forecast the occurrence of drought has become possible through the utilization of methods of remote sensing which work on satellite imagery data. Satellites are celestial bodies, such as the moon, that revolve in an orbit surrounding planets. Since the 60s, people have made artificial satellites, which are spacecrafts that orbit the earth, to meet many purposes such as telecommunication and the acquisition of surface images of the earth [4]. Earth surface imagery are useful to analyze the shape of the earth and the changes of its surface and objects thereon. From satellite imagery, people may reveal the occurrence of forest fire, flood, landslide, and drought.

In addition to satellite imagery, drought forecast may be conducted based on rainfall data. A popular drought calculation method is based on rainfall, which is known as 
the Standardized Precipitation Index (SPI). According to Adidarma et al., calculation of SPI is based on the amount of monthly rainfall and is widely used in the world [5]. Lincoln Declaration states that there has been an increase in the frequency and level of drought so that standard benchmarks are needed to monitor the disaster. These benchmarks are important because they are used together in monitoring and managing climate risks around the globe. Based on the SPI benchmarks, drought is declared to start if SPI is below zero (negative) and the drought ends when SPI shifts to positive [6], [7].

This paper describes the results of a research that observes methods to analyze drought. The methods used include the Inverse Distance Weigted which processes remote sensing data, and least square time series which processes annual Standard Precipitation Index (SPI) data. The data processed is climate data for the Western Southeast Mollucan regency, in the province of South Maluku.

The Western Southeast Mollucan regency (MTB) often suffers from drought. The region is a tropical area close to the Pacific ocean. Generally, the weather in Indonesia is very sensitive to a climate anomaly called El Nino Southern Oscillation (ENSO). ENSO will cause low rainfall in Indonesia when the surface temperatures of the equatorial Pacific ocean in the middle area to the eastern part warms up [2]. According to the Head of the Center for Data, Information and Public Relations of the National Disaster Management Agency (BNPB), ENSO may cause drought in more than 4000 villages in Indonesia affecting around 4.87 million people [8]. The perceived impacts include the lack of clean water and the decline of food production. MTB regency is one of the areas that suffers the hardest hit by the ENSO climate anomaly. Drought may persists over a long period of time resulting in crop failure for maize, rice and tubers [9].

\section{Literature Review}

We observe several studies that have been carried out related to drought disasters. One of them was carried out by [10] who observed remote sensing for monitoring drought in paddy fields. They observed vegetation index (VI) of paddy fields in East Java and Bali during July to December 2011. The level of greenness of vegetation during eleven 8-day periods showed a domination of low VI. Low rainfall during July 2011 caused a shortage of water supply to paddy fields in several districts, especially during August and September. A low level VI indicates that the observed area suffers a drought.

Another study has examined the relationship between vegetation index and spatial position. The results of analysis suggest that drought phenomenon has spatial connectivity among the observed regions. K-means analysis shows that under the high vegetation density, the weight of the distance between vegetation data points and the centroid is shorter. That is, data are concentrated in an area. Under conditions of low vegetation density, the weight of the distance between the data points to the centroid becomes wider. Under such condition, the data looks more distributed. The dominance of the green data group shows the dominance of the grid that marks the vegetation. The dominance of brown and red data groups shows the dominance of the grid marking the nonvegetation surface area or low vegetation growth, which indicates drought [11].

Subsequent research looked at the use of Theory of Run in the Krueng watershed, Aceh. This research yields monthly rainfall calculations for various monitoring points in Aceh province [5].

\section{Research Methods}

\section{a. Research stages}

This research runs in several stages as shown in the flowchart in Figure 1. Satellite imagery on the flowchart is input data or observations from the remote sensing process. Remote sensing is usually defined as the science of obtaining information about an object, area or phenomenon through the analysis of data obtained through a device without direct contact with the object, area, or phenomenon [12].

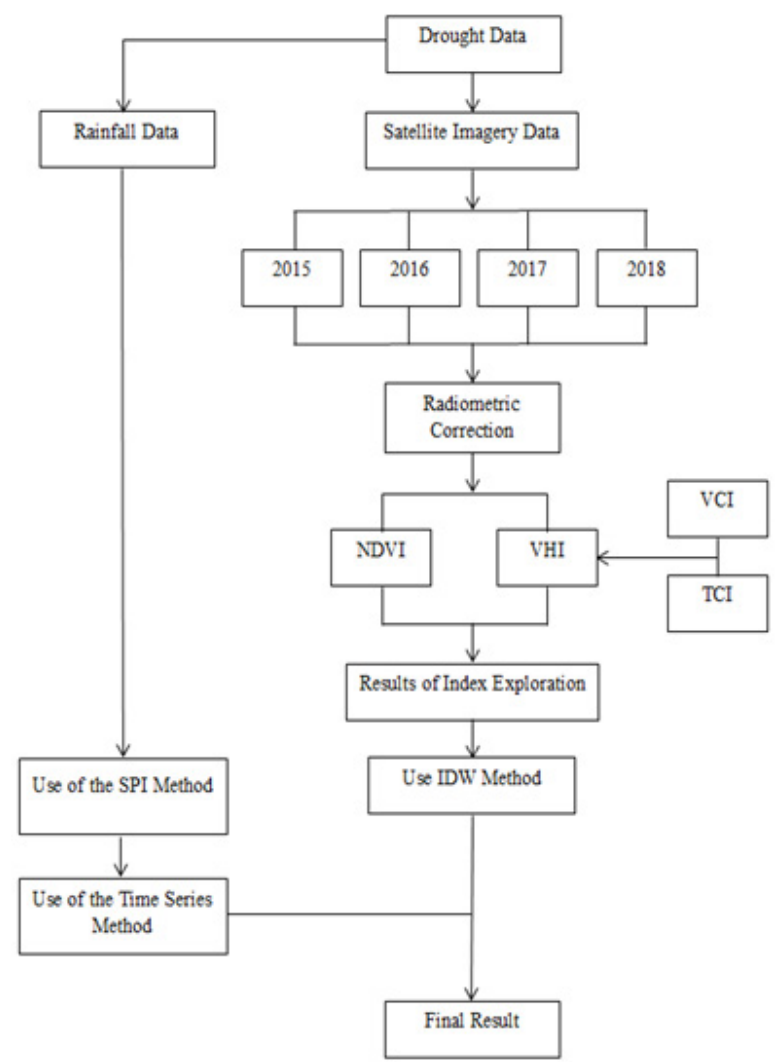

Figure 1. Research Flow; see text for description of acronyms

Normalized Difference Vegetation Index (NDVI) is a formula that is widely used to predict surface properties when the vegetation canopy is not too tight and not too rare. NDVI calculations are shown in equation (1) where 
NIR is the spectral value of the near infrared channel, and RED is the spectral value of the Red channel.

$$
N D V I=\frac{N I R-R E D}{N I R+R E D}
$$

Vegetation Health Index (VHI) is an index that describes the health of vegetation regardless of the cause. Poor vegetation health can be caused by stress due to drought, flooding, or pest attacks [5]. The VHI calculation is shown in equation (2) where VCI is the vegetation condition index, TCI is the temperature condition index, and parameter $\mathrm{a}$ is the contribution coefficient of the two indices [13].

$$
V H I=a \times V C I+(1-a) \times T C I
$$

Phase $\mathbf{1}$ is the data collection stage which includes data on drought events, both electronic news sites and BMKG, rainfall data at the location studied and satellite imagery data over an interval of four periods (2015-2018).

Phase $\mathbf{2}$ is the initial data processing stage which is the analysis phase using several formulations. At this stage, satellite image data is corrected, then processed using the index exploration processing method. The methods referred to are the Normalized Difference Vegetation Index (NDVI) and Vegetation Health Index (VHI).

Phase 3 is a drought analysis using the Inverse Distance Weighted (IDW) method which is applied to the results of index exploration processing. At this stage the SPI method is also applied to the rainfall data to get the standardized precipitation index. SPI calculation results are used to predict drought in 2019 using the least square time series method.

Phase 4 is the analysis of the results of the calculation of the drought prediction as the output of the two methods.

\section{b. Drought Analysis Method}

1) Inverse Distance Weighted

Inverse Distance Weighted (IDW) is a simple deterministic method by considering the points around it. Points closer to the estimated location will be given more weight than points further away. This weighting is the origin of the name inverse distance weighted [14]. Two points that are close together are said to be more similar than two points that are far apart.

The IDW method uses the centroid point which is the estimated sample point in each district. One point represents one weighting value for each district. In this study there were six centroid points according to the number of sub-districts in the area observed. The IDW formula is shown in equations (3) and (4) [15].

$$
u(x)=\sum_{i=0}^{N} \frac{w_{i}(x) u_{i}}{\sum_{j=0}^{N} w_{j}(x)}
$$

$w_{i}(x)=\frac{1}{d\left(x, x_{1}\right)^{p}}$

In both of these equations, $\mathrm{u}_{\mathrm{i}}=\mathrm{u}\left(\mathrm{x}_{\mathrm{i}}\right)$, for $\mathrm{i}$ from 0 to $\mathrm{N}$, $\mathrm{x}$ is an interpolated point, $\mathrm{x}_{\mathrm{i}}$ is a known point, $\mathrm{d}$ is the distance of point $\mathrm{x}$ with respect to $\mathrm{x}_{\mathrm{i}}, \mathrm{N}$ is the number of points, and $\mathrm{p}$ is power which is a positive real number.

\section{2) Standardized Precipitation Index}

The Standardized Precipitation Index (SPI) was developed in 1993 by McKee. The aim is to determine and monitor drought [16]. SPI is calculated as follows [17]. First determine the $\alpha$ and $\beta$ values estimated for each rain station monitoring point using equations (5) - (7).

$$
\begin{aligned}
& \alpha=\frac{1}{4 A}\left(1+\sqrt{1+\frac{4 A}{3}}\right) \\
& A=\frac{\ln (x)-\sum \ln (x)}{n} \\
& \beta=\frac{x}{\alpha}
\end{aligned}
$$

In equations (5), (6) and (7), ln is the natural logarithm, $\mathrm{x}$ the amount of rainfall and $\mathrm{n}$ the amount of rainfall observation data.

SPI value calculation is based on the gamma distribution which is defined as a function of frequency or chance of occurrence. For this reason, it is necessary to determine the value of $\mathrm{H}(\mathrm{x})$ following equation (8).

$H(x)=q+(1-q) \cdot G(x)$

In equation (8), $\mathrm{q}$ is the number of rainfall events, $0 / \mathrm{n}$ where $\mathrm{n}$ is the number of years of rainfall data, $\mathrm{G}$ is the gamma distribution, and $\mathrm{x}$ can be filled with $x, \alpha$, or $\beta$.

If $0<\mathrm{H}(\mathrm{x}) \leq 0.5$, the calculation of the SPI value follows equations (9) and (10).

$S P I=-\left(t-\frac{c_{0}+c_{1}+c_{2} t^{2}}{1+d_{1}+d_{2} t^{2}+d_{3} t^{3}}\right)$

$t=\sqrt{\operatorname{In} \frac{1}{(H(x))^{2}}}$

Calculation of the SPI value for $0.5<\mathrm{H}(\mathrm{x}) \leq 1.0$ follows equations (11) and (12).

$$
\begin{aligned}
& S P I=\left(t-\frac{c_{0}+c_{1}+c_{2} t^{2}}{1+d_{1}+d_{2} t^{2}+d_{3} t^{3}}\right) \\
& t=\sqrt{\operatorname{In} \frac{1}{1-(H(x))^{2}}}
\end{aligned}
$$

The coefficients in equations (9) and (11) have the following values.

$\mathrm{c}_{0}: 2.515517$

$c_{1}: 0.802853$ 
$\mathrm{c}_{2}: 0.010328$

$\mathrm{d}_{0}: 1.432788$

$\mathrm{d}_{1}: 0.189269$

$\mathrm{d}_{2}: 0.001308$

SPI values indicate the value of rainfall compared to average rainfall. A positive SPI value indicates rainfall at a time greater than average rainfall. Conversely, a negative SPI value indicates rainfall at a time smaller than average rainfall [16].

\section{3) Time Series}

Time series is a collection of data collected in a time span, or data whose independent variable is time. Time series data is usually used to forecast (value) the value of the dependent variable for future events. Forecasting is done on the basis of scientific methods (science and technology) and carried out systematically [18].

Least Square is a method for determining relationships between variables, in the form of the most appropriate mathematical equation. This method minimizes the number of errors between the data points and the equation curve points. Least Square produces the most appropriate trend line (best fit) from time series data [19], [20]. Mathematically, the trend line can be expressed with equation (13).

$Y=a+b x$

In equation (13), $\mathrm{Y}$ is the value of the forecast result, a basic period, $b$ the rate of development of the predicted value, $\mathrm{x}$ the time calculated, and $\mathrm{n}$ the number of years predicted. Coefficients a and b are calculated based on past drought data by following equations (14) and (15) [20].

$a=\frac{\sum y}{n}$

$b=\frac{\sum x}{\sum x^{2}}$

\section{c. Research sites}

This study takes data on drought and rainfall for Western Southeast Mollucan (MTB) districts, namely in the districts of Nirunmas, Kormomolin, Wer Tamrian, and South Tanimbar. Geographically, MTB is located at coordinates 6o34'24" - 8o24'36" South Latitude and 130 o37'47" - 133o4'12" East Longitude. The total area is $52,995.20 \mathrm{~km}^{2}$ which consists of land area of $10,102.92$ $\mathrm{km}^{2}(19.06 \%)$ and water area of 42,892.28 km² (80.94\%).

\section{Results And Discussion}

Before calculating the exploration index, the researcher first carries out radiometric correction to correct the pixel values to match what they should be. Correction is needed to reduce image errors due to atmospheric factors which are the main source of errors. Radiometric correction is done by converting a number value into a reflectance value.

\section{a. Exploration Index Calculation}

The radiometric corrected image was processed using two exploration index methods, namely NDVI and VHI. Figure 2 shows the results of the NDVI (green) exploration index calculation and Figure 3 shows the results of the VHI (drought) calculation in the Western Southeast Mollucan (MTB) region. The four sub-districts of Nirunmas, Kormomolin, Wer Tamrian and Tanimbar Selatan are shown in a row in a row from north to south.

The final results of the calculation of vegetation index in the form of numbers are presented in table 1 . The first row of the table contains the final results of calculating the index with NDVI (greenness) and the second row contains the final results of calculations with VHI (drought). The results of calculations are carried out on satellite imagery for a period of four years, namely in the range of 2015-2018.
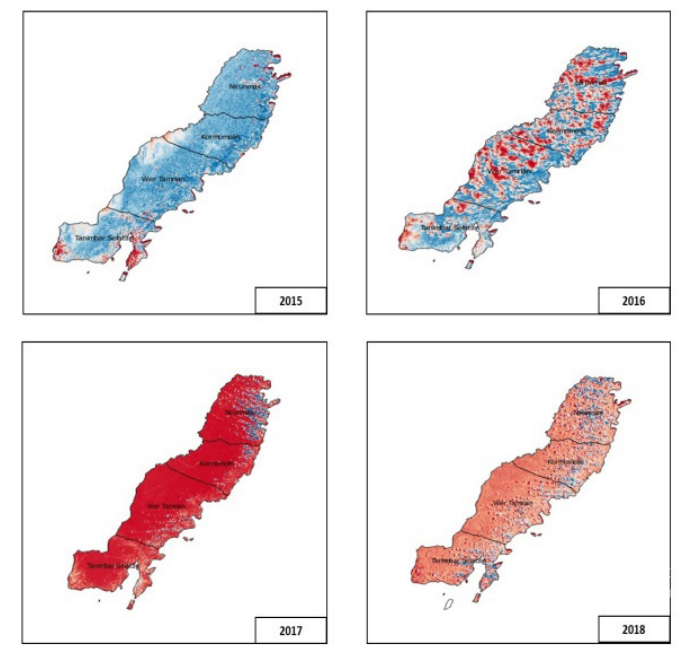

Figure 2. NDVI image during 2015-2018
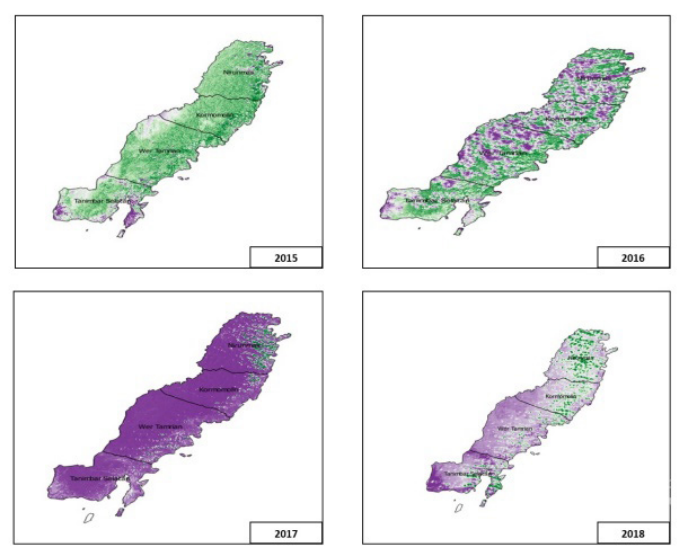

Figure 3. VHI image during 2015-2018 
Table 1. Calculation result of exploration Indices

\begin{tabular}{ccccc}
\hline Year & $\mathbf{2 0 1 5}$ & $\mathbf{2 0 1 6}$ & $\mathbf{2 0 1 7}$ & $\mathbf{2 0 1 8}$ \\
\hline NDVI & 0.40 & 0.31 & 10.31 & 41.62 \\
VHI & 26.46 & 25.16 & 26.58 & 51.08 \\
\hline
\end{tabular}

The NDVI index in 2015 and 2016 shows that vegetation is rare in MTB. Whereas the index in 2017 and 2018 shows dense vegetation. Meanwhile, the VHI index in 2015, 2016 and 2017 shows the level of severe drought occurring in the area under study. But in 2016 there was a decrease in the VHI index by 1.3 , which means an increase in drought, which can be attributed to the $\mathrm{El}$ Nino phenomenon in 2015. In 2017, the VHI index value was higher than the previous two years, which means relatively low drought. Whereas in 2018 the VHI value is very high which indicates no drought in MTB.

The exploration index calculation for the MTB district shows that this area had a severe level of drought in 2015-2017. The NDVI index shows rare vegetation which can be interpreted as a possibility of drought. The NDVI index for 2018 shows that dense vegetation means that there is no drought. This indication is in accordance with the results of the VHI index calculation which states that in 2018 there will be no drought.

\section{b. Drought Analysis}

Drought analysis in this study was carried out using two methods namely the Distance Weighted Index (IDW) and the Standardized Precipitation Index (SPI). IDW calculation requires a centroid point value which contains a weighting value, which is a condition of applying IDW calculation in the QGIS application. Calculations using the IDW method in this study use the results of the VHI index calculation to examine the pattern of drought that occurs in each district in the area studied. The IDW calculation results are displayed in Figures 4 and 5.

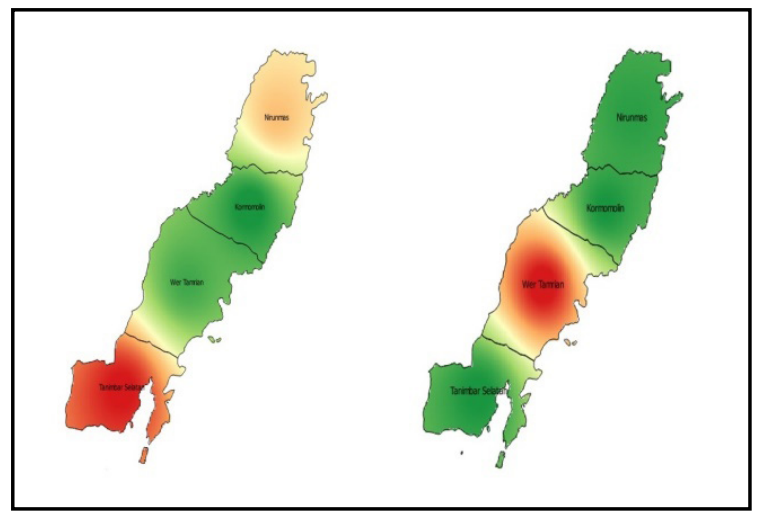

Figure 4. IDW calculation for year 2015 (left) and 2016 (right)

Figure 4 is the result of processing with the IDW method for data in 2015 and 2016. In 2015, Nirunmas sub-district (located the northernmost on the map) had moderate to mild drought levels dominated by mild drought levels. In that year the Kormomolin sub-district experienced a mild level of drought in the range of 3040, while the Wer Tamrian sub-district experienced a moderate to mild drought in the range of 20-30. While South Tanimbar sub-district has a drought level of 1030 which is included in the category of moderate-severe drought dominated by severe drought.

In 2016, all Nirunmas sub-districts experienced a moderate level of drought with an IDW value of 25.4. Kormomolin District has moderate to severe drought. While Wer Tamrian sub-district has a level of drought less than 10-20 which is included in the category of severe-extreme drought dominated by severe drought. Lastly, South Tanimbar district has moderate to severe drought.

Figure 5 shows the results of IDW calculations for 2017 and 2018. In 2017, Nirunmas sub-district did not experience drought even though there were some regions that experienced mild to moderate drought. Kormomolin District has mild to severe drought levels while Wer Tamrian and South Tanimbar districts have severe drought levels in the range of 10-20. While in 2018, the IDW calculation results for the four districts produce 45.5-69.3 which means that it is included in the category of no drought. The results of IDW interpretation for the four sub-districts in the MTB district over a span of four years can be seen in table 2 .

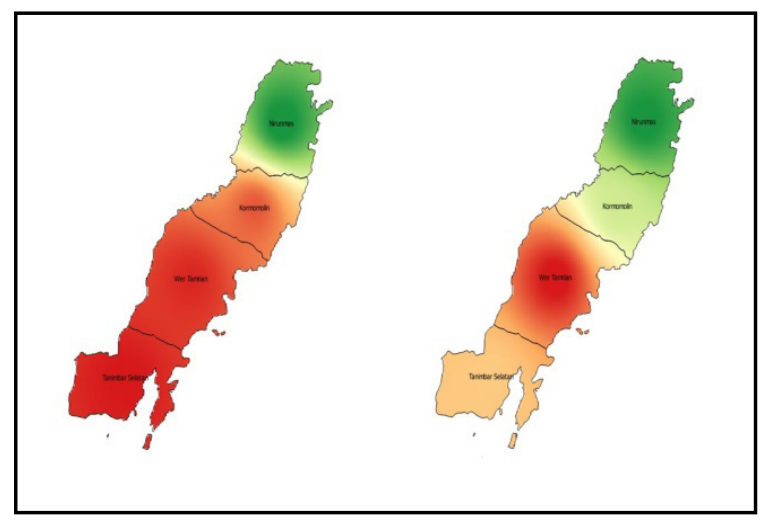

Figure 5. IDW calculation for year 2017 (left) and 2018 (right)

Table 2. Drought Analysis by IDW Method

\begin{tabular}{cc}
\hline Year & Drought Level \\
\hline 2015 & Mild-Severe \\
2016 & Moderate-Extreme \\
2017 & Mild-Severe \\
2018 & No Dryness \\
\hline
\end{tabular}

Table 3 shows the results of applying the SPI method to rainfall data in MTB. The MTB Regency only has one rain monitoring post so the available data is considered to represent one district data, and there is no data available per district. The data in the table states that the MTB district experienced drought only in 2015. In 2016 and 2017 there was no drought in the area, moreover in 2018 MTB experienced a wetter climate. 
Table 3. Drought Analysis by SPI Method

\begin{tabular}{lcc}
\hline Year & SPI Value & Conditions \\
\hline 2015 & -1.56 & Very Dry \\
2016 & 0.33 & Normal \\
2017 & 0.25 & Normal \\
2018 & 1.15 & Quite Wet \\
\hline
\end{tabular}

The results of the IDW and SPI analysis show results that are not entirely uniform. Both methods produce similar analyzes for the 2015 and 2018 data. However, both methods provide different analysis results for the 2016 and 2017 . data. Table 4 shows a comparison of interpretations of the level of drought produced by the two methods..

Table 4. Drought Level Comparison

\begin{tabular}{cccc}
\hline \multirow{2}{*}{ Year } & \multicolumn{2}{c}{ Drought level } & $\begin{array}{c}\text { Level } \\
\text { Similarity }\end{array}$ \\
\cline { 2 - 3 } & IDW & SPI & Similar \\
2015 & Mild-Severe & Very Dry & Dimferent \\
2016 & Moderate-Extreme & Normal & Different \\
2017 & Mild-Severe & Normal & Different \\
2018 & No Dryness & Quite Wet & Similar \\
\hline
\end{tabular}

For 2015, both methods provide the results of calculations that are interpreted as a occurrence of drought. Whereas in 2018, the results of the calculation of the two methods are interpreted in the same way that there is no drought. However, analysis results for 2016-2017 show different results between the IDW and SPI methods. According to the IDW method, in the range of 2016-2017 there was a drought in MTB while the results of the calculation of the SPI method stated there was no drought [11].

The difference in the results of the analysis of the two methods allegedly caused by differences in the sample of data used in the analysis. IDW method uses satellite imagery so that the data obtained are in the form of two-dimensional data consisting of many monitoring points. Meanwhile, the SPI method uses rainfall data at one point in the district of MTB so that it may not necessarily represent events in land areas covering more than 10 thousand square kilometers.

\section{c. Drought Forecast}

Forecasting drought is beneficial for the government and residents to anticipate the weather with activities that can be carried out in these weather conditions. Because the data obtained from drought analysis is time-based data, forecasting the level of drought in the future can be done using the time series method. One method that is quite simple to apply is least square, which models the weather with a trend line.

This study uses the least square time series approach to predict the level of drought in 2019 based on drought data in the range of 2015-2018. Annual data is refined into quarter data so that 12 drought levels are obtained over a four-year period (see Figure 6
Step 1). The least square time series calculation is done with the R-Studio and Excel applications. The step taken is to calculate the average value of each quarter and the total value per year (see figure 6 step 2). Then the values of $Y$ and X (figure 6 step 3 ) are determined.

Least square time series is applied in the form of determining the trend line following equation (13) where the coefficient values $\mathrm{a}$ and $\mathrm{b}$ are calculated using equations (14) and (15). The calculation process appears in Figure 7 step 4. Using the trend line, the value of the drought level in 2019 can be predicted (see Figure 7 step 5). Furthermore, the predicted value for each quarter for 2019 is done by looking at the average index for each quarter for 2015-2018 (figure 7 step 6) where it is assumed that the value for each quarter in 2019 will be the same as the average value for each quarter in 2015- 2018. The quarterly index forecast results for 2019 are shown in figure 7 step 7 .

1 \begin{tabular}{|l|r|r|r|}
\hline Year & Quarter I & \multicolumn{1}{c|}{ Quarter II } & Quarter III \\
\hline 2015 & 4.12 & 4.12 & -1.56 \\
\hline 2016 & 2.84 & 2.85 & 0.33 \\
\hline 2017 & 2.53 & 2.94 & 0.25 \\
\hline 2018 & 1.84 & 2.13 & 1.15 \\
\hline
\end{tabular}

\begin{tabular}{r|r|r|r|r|}
\hline Year & \multicolumn{1}{|c|}{ Quarter I } & \multicolumn{1}{c|}{ Quarter II } & Quarter III & Total Yearly \\
\hline 2015 & 4.12 & 4.12 & -1.56 & 6.68 \\
\hline 2016 & 2.84 & 2.85 & 0.33 & 6.02 \\
\hline 2017 & 2.53 & 2.94 & 0.25 & 5.72 \\
\hline 2018 & 1.84 & 2.13 & 1.15 & 5.12 \\
\hline Total & 11.33 & 12.04 & 0.17 & \\
\hline Average & 2.8325 & 3.01 & 0.0425 & \\
\hline
\end{tabular}

\begin{tabular}{c|c|r|r|r|r|}
\hline Year & \multicolumn{1}{|c|}{ SPI(Y) } & \multicolumn{1}{|c|}{ X } & \multicolumn{1}{|c|}{ XY } & \multicolumn{1}{|c|}{$\mathbf{X}^{2}$} \\
\hline 2015 & 6.68 & -3 & -20.04 & 9 \\
\hline 2016 & 6.02 & -1 & -6.02 & 1 \\
\hline 2017 & 5.72 & 1 & 5.72 & 1 \\
\hline 2018 & 5.12 & 3 & 15.36 & 9 \\
\hline$\Sigma$ & 23.54 & 0 & -4.98 & 20 \\
\hline
\end{tabular}

Figure 6. Forecasting SPI index using least square time series step 1-3

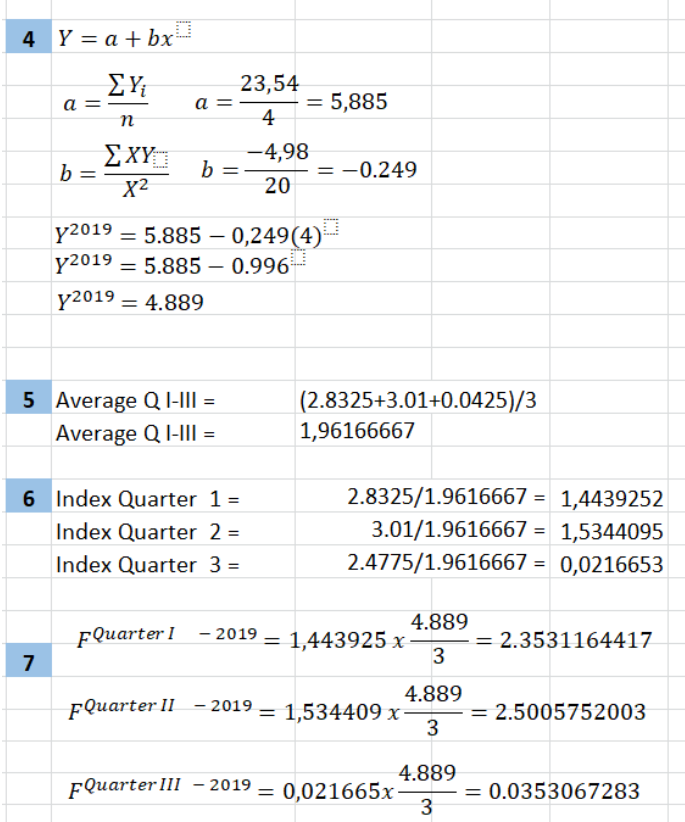

Figure 7. Forecasting SPI index using least square time series step 4-7 
SPI index values for 2015-2018 and forecast results for 2019 are presented in table 4. The same values in graphical form are presented in figure 8 . According to table 4, in 2019 from the first quarter to the third quarter there was no drought (more index values from 0 ). Values $0-2.5$ has the meaning of normal to wet weather. The results of this forecast are in accordance with field observations made by researchers.

Table 4. SPI Index in 2015-2018 and its forecast for year 2019

\begin{tabular}{cccc}
\hline Year & Quarter I & Quarter II & Quarter III \\
\hline 2015 & 4.12 & 4.12 & -1.56 \\
2016 & 2.84 & 2.85 & 0.33 \\
2017 & 2.53 & 2.94 & 0.25 \\
2018 & 1.84 & 2.13 & 1.15 \\
2019 & 2.35 & 2.5 & 0.03 \\
\hline
\end{tabular}

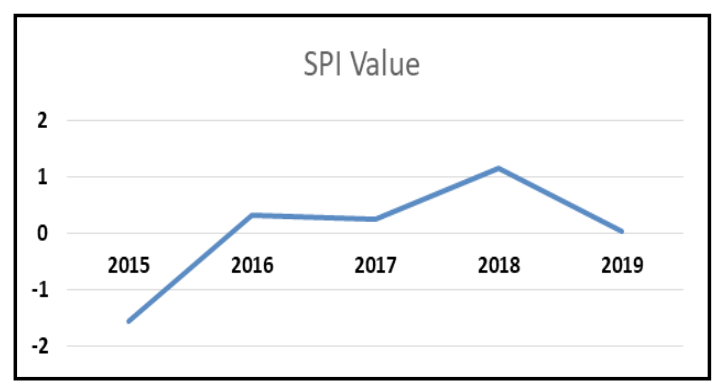

Figure 8. SPI Value during year interval 2015-2019

\section{Conclusion}

Description in the results and discussion section suggests that satellite imagery can be used to observe the occurrence of drought in an area. The NDVI and VHI index calculation results provide similar interpretation results related to drought in Western Southeast Mollucan (MTB). However, IDW analysis based on satellite imagery and SPI analysis using rainfall data give results that are not entirely the same. In the span of 4 years of observation, the two analytical methods give similar results for the 2015 and 2018 data, but give different results for the 2016 and 2017 data. This difference is caused by the number of data points under consideration. Satellite imagery has many data points whereas rainfall data only has one point for the whole area of MTB.

The least square time series method can be used to forecast the occurence of drought by utilizing drought index data in the past years to calculate drought index for the future. Drought forecast based on SPI data in the period of 2015-2018 gives the SPI index value at 0.03 for 2019. SPI index at such a level is interpreted as no drought, which fully agrees with the result of our field observation.

\section{Reference}

[1] R. D'Arrigo and R. Wilson, "El Nino and Indian Ocean influences on Indonesian drought: implications for forecasting rainfall and crop productivity," Int. J. Climatol. A J. R. Meteorol.
Soc., vol. 28, no. 5, pp. 611-616, 2008.

[2] I. G. Hendrawan, K. Asai, A. Triwahyuni, and D. V. Lestari, "The interanual rainfall variability in Indonesia corresponding to El Niño Southern oscillation and Indian Ocean Dipole," Acta Oceanol. Sin., vol. 38, no. 7, pp. 57-66, 2019.

[3] L. Arumingtyas, "Jawa dan Nusa Tenggara Langganan Bencana Kekeringan, Mengapa?," Mongabay, 2018.

[4] A. Sulistyo, "Kombinasi Teknologi Aplikasi GPS Mobile dan Pemetaan SIG dalam Sistem Pemantauan Demam Berdarah (DBD)," Khazanah Inform. J. Ilmu Komput. dan Inform., vol. 5, no. 1, pp. 6-14, 2019.

[5] A. Syahrial, A. Azmeri, and E. Meilianda, "Analisis Kekeringan Menggunakan Metode Theory of Run di DAS Krueng Aceh,” J. Civ. Eng., vol. 24, no. 2, pp. 167-172, 2017.

[6] L. Wang, G. Huang, and W. Chen, "Towards a theoretical understanding of multiscalar drought indices based on the relationship between precipitation and standardized precipitation index," Theor. Appl. Climatol., vol. 136, no. 3-4, pp. 1465-1473, 2019.

[7] W. Hatmoko, "Indeks Kekeringan Hidrologi untuk Alokasi Air di Indonesia.” Puslitbang Sumber Daya Air, Bandung, 2012.

[8] M. Hendartyo, "BNPB: 4,87 Juta Jiwa Terdampak Kekeringan,” Tempo, 07-Sep-2018.

[9] Saumlaki, "Maret, Kelaparan Ancam MTB Akibat Krisis Air Parah,” Dhara Pos, 02-Mar-2016.

[10] A. Zubaidah, D. Dirgahayu, and J. M. Pasaribu, "Penginderaan jauh untuk pemantauan kekeringan lahan sawah,” J. Ilm. Widya, vol. 1, no. 1, 2014.

[11] S. Y. J. Prasetyo, K. D. Hartomo, B. H. Simanjuntak, and D. W. Candra, "Mitigation \& identification for local aridity, based of vegetation indices combined with spatial statistics \& clustering k means," in Journal of Physics: Conference Series, 2019, vol. 1235, no. 1, p. 12028.

[12] R. P. Gupta, Remote sensing geology. Springer, 2017.

[13] V. A. Bento, I. F. Trigo, C. M. Gouveia, and C. C. DaCamara, "Contribution of land surface temperature (TCI) to vegetation health index: A comparative study using clear sky and all-weather climate data records," Remote Sens., vol. 10, no. 9, p. 1324, 2018.

[14] S. M. Indirawati, S. Pandia, H. Mawengkang, and W. Hasan, "Inverse Distance Weighted Method and Environmental Health Risks of Plumbum Pollution in Drinking Water in Belawan Coastal Area," Adv. Sci. Lett., vol. 23, no. 4, pp. 33393343, 2017. 
[15] S. R. Fitri, E. Saadudin, B. Pranoto, and others, "Comparison of Inverse Distance Weighted (IDW), Natural Neighbour, and Spline Interpolation Methods for Downscaling Data of Solar Energy Potential Map," Ketenagalistrikan dan Energi Terbarukan, vol. 13, no. 1, pp. 27-38, 2014.

[16] R. Kumar, M. Majid, S. Mir, and M. Shahzad, "Temporal analysis of drought using standard precipitation index (SPI) method," Indian J. Soil Conserv., vol. 45, no. 3, pp. 348-350, 2017.

[17] I. A. Andika, "Penerapan Metode Standardized Precipitation Index (SPI) untuk Analisa Kekeringan di DAS Ngasinan Kabupaten Trenggalek," Universitas Brawijaya, 2016.

[18] P. J. Brockwell and R. A. Davis, Introduction to time series and forecasting. springer, 2016.

[19] P. K. Pradhan, S. Dhal, and N. K. Kamila, "Time series least square forecasting analysis and evaluation for natural gas consumption," Int. J. Recent Innov. Trends Comput. Commun., vol. 5, no. 11, pp. 91-99, 2017.

[20] F. R. Hariri, "Metode Least Square Untuk Prediksi Penjualan Sari Kedelai Rosi," Simetris J. Tek. Mesin, Elektro dan Ilmu Komput., vol. 7, no. 2, pp. 731-736, 2016. 